Joseph P. Janik · Joseph S. Janik · Eli R. Wayne Alfonso Pantoja

\title{
Familial occurrence of congenital diaphragmatic hernia
}

\author{
Father-to-son inheritance
}

Accepted: 13 June 1995

\begin{abstract}
Familial occurrence of congenital diaphragmatic hernia is rare. This is only the second case of parent-to-child inheritance and the first case of father-to-son inheritance. The available data point toward a multifactorial mode of genetic transmission.
\end{abstract}

Key words Congenital diaphragmatic hernia $\cdot$ Familial inheritance

\section{Introduction}

It is well known that the development of a congenital diaphragmatic hernia (CDH) appears to be the result of a failure of the pleuroperitoneal folds to completely fuse [14]. The etiology of the defect remains unknown, though both non-genetic $[1,3,8,11,12,15$, $22,29]$ and genetic factors $[2,4-7,10$, 13, 14, 16-21, 23-28, 30] have been implicated. Polybrominated diphenyls

\section{J. P. Janik}

College of Literature, Science, and Arts, University of Michigan, Ann Arbor, MI, USA

J. S. Janik - E. R. Wayne

The Children's Hospital and St. Joseph's Hospital, Denver, CO, USA

J. S. Janik - E. R. Wayne

University of Colorado Health Sciences

Center, Denver, CO, USA

A. Pantoja

St. Joseph Hospital, Denver, CO, USA

\section{J. S. Janik (}

The Children's Hospital, 1950 Ogden,

HC 330, Denver, CO 80218, USA
[3], thalidomide [8], nitrofen [12], quinine [15], and phenometrazine $[11,12]$ have been used to induce $\mathrm{CDH}$ in the embryos of different species. Warkany and Roth [28] and Anderson [1] have implicated maternal dietary deficiency of vitamin $A$ as a cause of $\mathrm{CDH}$ in rat fetuses. To date, no specific agent has been demonstrated to cause $\mathrm{CDH}$ in humans.

The genetic theories explaining the etiology of $\mathrm{CDH}$ are numerous and are based on familial case reports $[2,4-7$, $9,10,13,14,16-21,23-28,30]$. the incidence of familial cases is less than $2 \%$ of all cases of $\mathrm{CDH}[5,17,23]$, thus limiting the material supporting the genetic theories. The first reported familial case was published in 1916 by Makela [19]. Since then, over 30 families with over 60 affected members have appeared in the literature [20]. These reports have described identical twins (individual monozygotic and dizygotic pairs), siblings, half-siblings, a maternal uncle of affected siblings, cousins, offspring of consanguineous parents, and even two members of a set of triplets $[2,4-7,9,10,13,14$, $16-21,23-28,30]$. In 1994 Frey et al. reported the first case of paternal-tooffspring (father-to-daughter) transmission [9]. The present report is the second to document paternal-to-offspring transmission and the first report of father-to-son inheritance.

\section{Case reports}

Father

In 1954, in St. Louis, Missouri, a 3,100-g male was born after an uncomplicated 40 week gestation. $\mathrm{He}$ was discharged after 4 days. Because of slow feeding he was diagnosed as having a "spastic stomach." At 4 months of age severe cramping abdominal pain and vomiting occurred. A chest X-ray film (Fig. 1) demonstrated a left $\mathrm{CDH}$. At exploration, the bowel was reduced via a subcostal incision and the hernia repaired. Postoperatively, the child did well and had no problems. Since this child was adopted, his parents' family and medical history were unavailable. At 35 years of age, he fathered a son with CDH. He has had three other children, two males and one female, who are completely normal.

Son

In 1989, in Denver, Colorado, a 2,450-g male was born after a 38-week gestation. A second trimester ultrasound scan revealed a left $\mathrm{CDH}$ At birth he had severe respiratory distress. A chest X-ray film (Fig. 2) confirmed a left $\mathrm{CDH}$. At exploration, the bowel was reduced via a subcostal incision and the hernia was repaired under tension with an abdominal muscle flap. The subcostal incision was closed with skin only. The lung was "small" in size. Postoperatively, he had a stormy course characterized by severe respiratory insufficiency. Over the next 4 years he had a repair of the incisional hernia, several central venous catheters, multiple bronchoscopies, a laparotomy for adhesiolysis, a gastrostomy, a feeding jejunostomy, a Nissen fundoplication, repair of a recurrent $\mathrm{CDH}$, a tracheostomy, repair with Marlex of a second recurrent $\mathrm{CDH}$, and an orchiopexy. His lung status has remained tenuous, requiring supplemental oxygen, and his weight has been consistently below the 5th percentile despite multiple feeding regimes. His three siblings, his 

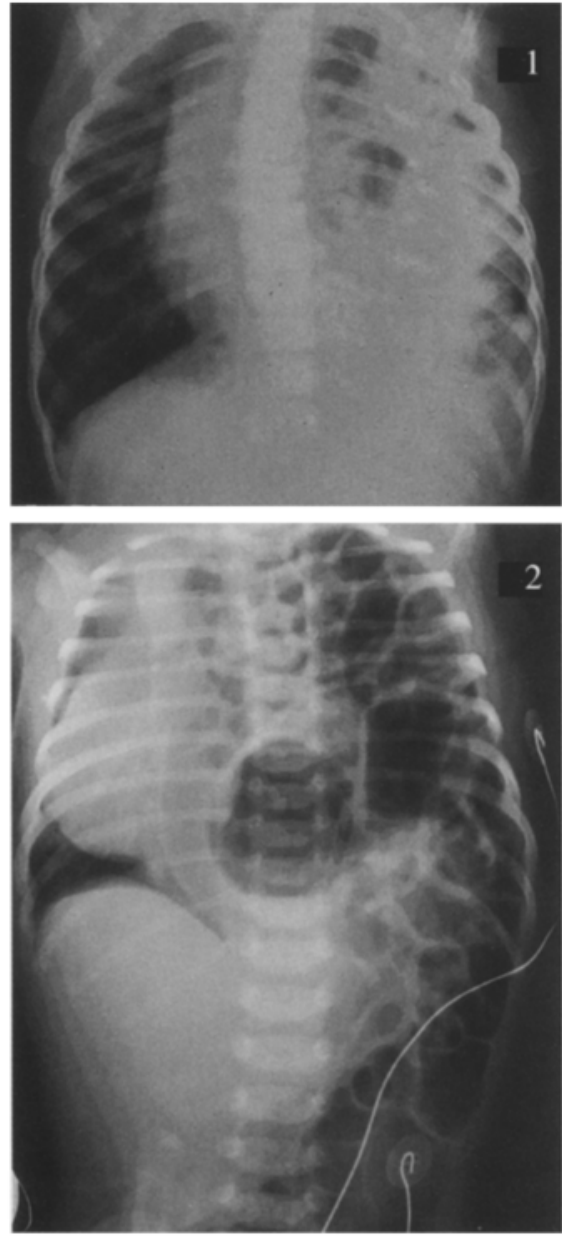

Fig. 1 AP chest film demonstrating left diaphragmatic hernia in a 4-month-old male (father)

Fig. 2 AP chest film demonstrating left diaphragmatic hernia in a newborn male (son)

mother, and his mother's family are free of any $\mathrm{CDH}$ or history of congenital anomaly.

\section{Discussion}

Although a CDH occurs once in every $2,000-3,000$ births [23], the familial form is much less common, being estimated at approximately $1 \%-2 \%$ of all forms of $\mathrm{CDH}[5,17,23]$. Familial $\mathrm{CDH}$ is so uncommon that it is not even mentioned in Smith's treatise on human malformations [25]. This paucity of clinical material has limited scholars' ability to elucidate the pattern of inheritance of familial $\mathrm{CDH}$ and provide adequate genetic counseling.
In 1968 Passarge et al. [21] postulated that familial $\mathrm{CDH}$ is a distinct entity with autosomal recessive transmission. Support for this suggestion came from Arad et al. [2] in a report of children of consanguineous parents. In 1979 Crane [4] provided evidence for sex-linked or autosomal dominant transmission with incomplete penetrance as the mode of inheritance. However, his explanation did not account for all of the occurrences in extended pedigrees [17]. In 1985 Toriello et al. [27] reported two siblings with pulmonary and diaphragmatic agenesis. He concluded that they represented a previously unreported autosomal recessive condition affecting either multiple developmental fields or a single complex polytopic field. Czeziel and Kovacs [5] agreed with Arad that a high rate of cousin consanguinity among parents of children with familial $\mathrm{CDH}$ might indicate autosomal recessive inheritance. Yet, reports of familial $\mathrm{CDH}$ associated with consanguinity are sparse. Nonetheless, consanguinity [27] and multiple fatal anomalies associated with $\mathrm{CDH}[5,16,27]$ may represent a separate subtype of familial $\mathrm{CDH}$ that is autosomal recessive in origin.

Support for multifactorial inheritance has come from the large variety of familial CDHs reported by David and Illingworth [7], Lipson and Williams [17], Schubert-Staudacher and Jauch [24], and Wolff [30]. They concluded that the male predominance in familial $\mathrm{CDH}$ [20], the compatibility of all the pedigrees including halfsiblings [17], the paucity of consanguineous cases [2], the small number of familial CDHs relative to the sporadic CDHs [5, 20], and the heterogeneity of the anatomic findings and the associated anomalies [1-30] support the multifactorial mode of inheritance. Reports describing passage between generations have been limited to two maternal uncles of affected siblings $[16,20]$.

In 1994 Frey et al. [9] reported the first case of parent-to-offspring, fatherto-daughter transmission. They felt that their familial CDH represented the "missing part" in the chain of support for the multifactorial inheritance of familial $\mathrm{CDH}$. The present report of parent-to-offspring transmission supports Frey et al.'s opinion, eliminates the possibility that their report is a solitary chance occurrence, and adds the dimension of father-toson transmission to the collage of familial $\mathrm{CDH}$ s in the literature. Currently, there are no reports of maternalto-offspring inheritance.

Genetic counseling for parents with offspring with $\mathrm{CDH}$ should be tailored to the situation. Unless the offspring are of consanguineous origin or have multiple fatal anomalies, the chances of another child having $\mathrm{CDH}$ among first-degree relatives is $1 \%-2 \%[5,9$, $17,23]$. If there is any suspicion of autosomal recessive transmission, as in offspring of consanguineous parents or cases of multiple fatal anomalies, a $25 \%$ risk factor should be quoted $[2,21]$.

Since over $98 \%$ of CDHs are sporadic occurrences with no clear-cut teratogenic influence $[1,3,8,11,12$, $15,22,29]$, it is safe to conclude that this form of $\mathrm{CDH}$ is a developmental accident. Theories explaining familial CDH must include the cases of consanguineous parents [2] and multiple fatal anomalies associated with $\mathrm{CDH}$ $[5,27]$, the vast variety of familial presentations in the literature $[2,4$, $5-7,9,10,13,16-21,23-28,30]$, the variable size of the defects $[1-30]$, and the associated anomalies $[7,17$, 20]. Multifactorial inheritance is the only theory that comprehensively allows for the variations found among familial CDH.

\section{References}

1. Anderson DH (1949) Effect of diet during pregnancy upon the incidence of congenital hereditary diaphragmatic hernia in the rat. J Pathol 25: 163-185

2. Arad I, Lijovetsky GC, Staninsky R, et al (1980) Diaphragmatic defects in children of consanguineous parents. Hum Genet 55: $275-277$

3. Beaudoin AR (1977) Teratogenicity of polybrominated biphenyls in rat. Environ Rev 14: 81-86

4. Crane JP (1979) Familial congenital diaphragmatic hernia. Clin Genet 16: 244252

5. Czeizel A, Kovacs M (1985) A family study of congenital diaphragmatic defects. Am J Med Genet 21: 105-115 
6. Daentl DL, Passarge E (1972) Familial agenesis of the diaphragm. Birth Defects 8: $24-26$

7. David TJ, Illingworth CA (1976) Diaphragmatic hernia in the south-west of England. J Med Genet 13: 253-262

8. Drobeck HP, Coulston F, Cornelius D (1965) Effects of thalidomide on fetal development in rabbits and on establishment of pregnancy in monkeys. Toxicol Appl Pharmacol 7: 165-178

9. Frey P, Glanzmann PN, Herzog B (1974) Familial congenital diaphragmatic defect: Transmission from father to daughter. J Pediatr Surg 26: 1396-1398

10. Heron JC (1950) Familial diaphragmatic hernia. California Med 73: 457

11. Hobolth N (1962) Drugs and congenital abnormalities. Lancet II: $1333-1334$

12. Iritani I (1984) Experimental study on embryogenesis of congenital diaphragmatic hernia. Anat Embryol 169: 133 139

13. Kate LP ten (1970) Unilateral agenesis of the diaphragm. Humangenetik 8: 366367
14. Kluth D, Peterson C, Zimmermann HJ, et al (1989) The embryology of congenital diaphragmatic hernia. Mod Probl Paediatr 24: 7-21

15. Kup J (1967) Zwerchfelldefekt nach Abtreibungsversuch mit Chinin. München Med Wochenschr 27: 2582-2583

16. Lilly JR, Paul M, Rosser SB (1974) Anterior diaphragmatic hernia: familial presentation. Birth Defects 10: 257-258

17. Lipson AH, Williams G (1985) Congenital diaphragmatic hernia in half sibs. J Med Genet 22: 145-147

18. Locatelli L (1955) Analisi dei fattori ereditari dell'ernia diaphragmatica congenita. Folia Hered Pathol 4: 265

19. Makela V (1916) Hernia diaphragmatica congenita spuria. Finska Lak Sallsk Handl 58: 1107-1127

20. Mishalany H, Gordo J (1986) Congenital diaphragmatic hernia in monozygotic twins. J Pediatr Surg 21: 372-374

21. Passarge E, Halsey H, German J (1968) Unilateral agenesis of the diaphragm. Humangenetik 5: 226-230

22. Powell PD, Johnstone JM (1962) Phenometrazine and foetal abnotmalities. $\mathrm{Br}$ Med J II: 1327
23. Puri P (1989) Epidemiology of congenital diaphragmatic hernia. Mod Probl Paediatr 24: $22-27$

24. Schubert-Staudacher E, Jauch H (1984) Two sibs with bilateral diaphragmatic defect. Clin Genet 26: 485-487

25. Smith DW (1982) Recognizable patterns of human malformation 3rd edn. WB Saunders, Philadelphia, pp 1-653

26. Thomas MP, Stern LM, Morris LL (1976) Bilateral diaphragmatic defects in two siblings. J Pediatr Surg 11: 465-467

27. Toriello HV, Higgins JV, Jones AS, et al (1985) Pulmonary and diaphragmatic agenesis: report of affected sibs. Am J Med Genet 21: 87-92

28. Warkany J, Roth CB (1948) Congenital malformations induced in rats by maternal vitamin A deficiencies. J Nutr 35 : $1-11$

29. Watanatittan S (1983) Congenital diaphragmatic hernia in identical twins. J Pediatr Surg 18: 628-629

30. Wolff G (1980) Familial congenital diaphragmatic defect: review and conclusions. Hum Genet 54: 1-5 